\title{
Prediction of Severe Hypoglycaemia by Angiotensin-Converting Enzyme Activity and Genotype in Type 1 Diabetes
}

\author{
U. Pedersen-Bjergaard ${ }^{1,2}$, B. Agerholm-Larsen ${ }^{3}$, S. Pramming ${ }^{4}$, P. Hougaard ${ }^{4}$, B. Thorsteinsson ${ }^{2}$ \\ ${ }^{1}$ Department of Internal Medicine F, Hillerød Hospital, Hillerød, Denmark \\ 2 Department of Internal Medicine F, Hillerød Hospital, Denmark \\ ${ }^{3}$ Department of Clinical Biochemistry, Herlev University Hospital, Herlev, Denmark \\ ${ }^{4}$ Novo Nordisk A/S, Bagsværd, Denmark
}

\section{Abstract}

Aims/hypothesis. We have previously shown a strong relationship between high angiotensin-converting enzyme (ACE) activity, presence of the deletion $(D)$ allele of the $A C E$ gene and recall of severe hypoglycaemic events in patients with Type 1 diabetes. This study was carried out to assess this relationship prospectively.

Methods. We followed 171 adult outpatients with Type 1 diabetes in a one-year observational study with the recording of severe hypoglycaemia. Participants were characterised by serum ACE activity and $A C E$ genotype and not treated with ACE inhibitors or angiotensin II receptor antagonists.

Results. There was a positive relationship between serum ACE activity and rate of severe hypoglycaemia with a 2.7 times higher rate in the fourth quartile of ACE activity compared to the first quartile $(p=0.0007)$. A similar relationship was observed for the subset of episodes with coma (2.9 times higher rate in fourth quartile compared to first quartile; $p=0.048)$. The impact of serum ACE activity was most pronounced in C-peptide negative subjects (4.2 times higher rate in fourth quartile compared to first quartile; $p=0.003$ ), and in this subgroup carriers of the $D$ allele of the $A C E$ gene had higher rates of severe hypoglycaemia compared to the group homozygous for the insertion $(I)$ allele. In a multiple regression analysis high serum ACE activity and impaired awareness of hypoglycaemia were identified as the only significant predictors of severe hypoglycemia.

Conclusion. High ACE activity and the presence of the $D$ allele of the $A C E$ gene predict a high rate of severe hypoglycaemia in Type 1 diabetes. [Diabetologia (2003) 46:89-96]

Keywords Diabetes mellitus, Type 1 diabetes, hypoglycaemia, ACE, angiotensin, bradykinin, awareness, unawareness, counterregulation, $\mathrm{HbA}_{1 \mathrm{c}}$, C-peptide.
Following the Diabetes Control and Complications Trial [1] a growing demand for strict glycaemic control has emerged to avoid late diabetic complications in Type 1 diabetes. As a consequence the majority of patients with Type 1 diabetes experience mild hypoglycaemia on a regular basis and recent studies applying continuous glucose monitoring indicate that pa-

Received: 29 May 2002 / Revised: 2 August 2002

Published online: 18 December 2002

C) Springer-Verlag 2002

Corresponding author: U. Pedersen-Bjergaard, Department of Internal Medicine F, Hillerød Hospital, Helsevej 2, 3400 Hillerød, Denmark, E-mail: ulpebj@fa.dk tients with Type 1 diabetes spend as much as ten percent of the time at hypoglycaemic glucose levels [2]. To avoid progression of these frequent episodes into severe hypoglycaemia patients rely on maintenance of performance capacity [3] until hypoglycaemic symptoms are recognised and self-treated or until the next pre-scheduled meal is ingested.

Risk of severe hypoglycaemia is a major limiting factor for the achievement of good metabolic control [4] rendering prediction of individual risk of severe hypoglycaemia increasingly important. Loss of hypoglycaemic warning symptoms and blunted hormonal counterregulatory response are the most important known predictors of severe hypoglycaemia $[4,5]$. However, even patients at high risk according to these pa- 
rameters have a highly varying inter-individual susceptibility to severe hypoglycaemia. This is reflected by the fact that experience of severe hypoglycaemia is highly skewed within cohorts of patients with Type 1 diabetes and that previous severe hypoglycaemia is a major, yet unexplained, risk factor for future episodes [6], that suggests the influence of inherent, e.g. genetic, factors.

Hypoglycaemia and exercise share some common metabolic features. Thus, during endurance exercise, counterregulatory mechanisms similar to those of hypoglycaemia are activated to mobilise fuel. In healthy humans both antecedent exercise and antecedent hypoglycaemia attenuate symptoms and hormonal counterregulation during subsequent hypoglycaemia $[7,8]$. In elite endurance athletes, who like patients with Type 1 diabetes spend considerable time with limited fuel availability, performance capacity has been associated with the angiotensin-converting enzyme $(A C E)$ genotype as the insertion $(I)$ allele of the $A C E$ gene that confers low ACE activity, compared to the deletion $(D)$ allele [9], has been linked to superior performance capacity $[10,11,12]$.

This indicates a benefit of low ACE activity on performance when fuel supply is limited and prompted us to investigate the relation between ACE activity and risk of severe hypoglycaemia in Type 1 diabetes. In a hypothesis-generating retrospective survey, recall of severe hypoglycaemia was strongly related with both high serum ACE activity and $D D$ genotype of the $A C E$ gene [13]. The purpose of this study was to test the hypothesis that high ACE activity is a predictor of the risk of severe hypoglycaemia in patients with Type 1 diabetes.

\section{Subjects and methods}

Subjects and design. Consecutive adult ( $>18$ years of age) outpatients with clinical Type 1 diabetes for more than 2 years were included in a 1-year prospective observational study that took place from October 1999 to March 2001 at Hillerød Hospital. Type 1 diabetes was defined by insulin treatment from the time of diagnosis and unstimulated C-peptide less than $300 \mathrm{pmol} / \mathrm{l}$ or stimulated (venous blood glucose concentration $>12 \mathrm{mmol} / \mathrm{l}$ ) C-peptide less than $600 \mathrm{pmol} / \mathrm{l}$. Excluded from participation in the study were pregnant women, subjects on haemodialysis or suffering from concomitant malignant disease, and subjects treated with ACE inhibitors or angiotensin II receptor antagonists due to the interference of these drugs with the naturally occurring ACE activity. Of 260 patients invited to take part in the study, 209 (80\%) gave informed consent to participate and of these, 171 subjects $(82 \%)$ completed the study. During the study, $31(15 \%)$ withdrew their consent, one died, and six subjects $(3 \%)$ were excluded from the analysis due to initiation of ACE inhibitor treatment. The clinical characteristics of the participants (Table 1) did not differ from those of non-participants and dropouts (not shown). The study was approved by the regional Ethics Committee.

Base-line data. At base-line, an extended version of a questionnaire originally developed by another study [14] was com- pleted by the participants to assess previous experience of hypoglycaemia and self-estimated state of hypoglycaemic awareness. State of awareness was classified according to the patients' ability to recognise symptoms, during a hypoglycaemic episode. Subjects always recognising their symptoms were categorised as having normal awareness, those usually recognising their symptoms as having impaired awareness, and those occasionally or never recognising their symptoms as having unawareness. There is at present no consensus on classification of awareness of hypoglycaemia and we chose this very simple method as it can be applied to almost all patients, it is easily translated and has been used by a number of groups [14, 15, 16], either alone or as part of scoring systems. Furthermore, with regard to the clinical consequence of impaired awareness, i.e. risk of severe hypoglycaemia, it discriminates between groups of patients as good as other methods $[13,15,16]$. Data on a patients' history of diabetes were extracted from medical records [13].

Laboratory analyses. At baseline, a blood sample was taken to characterise the participant. ACE genotype was assessed by polymerase chain reaction, including a check for misclassification of $D D$ subjects using an insertion specific primer as [17]. Serum ACE activity was assessed by a kinetics-based assay (Sigma Diagnostics, St. Louis, Miss., USA). C-peptide was measured by radioimmunoassay (Autodelfia, Wallac Oy, Turku, Finland). Subjects were classified as being C-peptide negative if the value was below the detection limit of $10 \mathrm{pmol} / \mathrm{l}$. $\mathrm{HbA}_{1 \mathrm{c}}$ was measured spectrophotometrically (DCA2000, Bayer, Leverkusen, Germany; normal range 4.1\%-6.4\%; standardised against the Diabetes Control and Complications Trial) at each visit at the outpatient clinic and individual average values for the study period were calculated.

Reporting and classification of hypoglycaemia. Hypoglycaemia was reported monthly on questionnaires mailed to the participants. Events of severe hypoglycaemia, defined as episodes with symptoms of hypoglycaemia with need for assistance from another person, were reported by telephone within $24 \mathrm{~h}$ after the event. Structured telephone interviews were carried out blind to ACE status of the patients to establish the level of documentation, classify severity, and explore circumstances of the incidents. At the end of follow-up severe hypoglycaemia was reported retrospectively and in the case of missed reporting, telephone interviews were carried out.

Episodes of severe hypoglycaemia were validated according to Whipple's: (i) symptoms of hypoglycaemia; (ii) blood glucose below $3 \mathrm{mmol} / \mathrm{l}$; and (iii) adequate response to glucose/glucagon treatment. Episodes fulfilling all criteria were classified as definite, those fulfilling two criteria with no alternative explanation of the symptoms were classified as probable and those with a concurring explanation fulfilling two criteria and those fulfilling only one criterion were classified as possible. Episodes recorded retrospectively were degraded by one class. Severity was sub-classified according to level of assistance and consciousness during the episode: (i) conscious during the event, but with need of assistance to treat orally; (ii) parenteral treatment necessary and/or coma or seizure during the event.

Mild hypoglycaemia was defined as episodes with symptoms familiar to the patient as hypoglycaemia and managed solely by the patient. These episodes were reported for the week preceding the return of the monthly questionnaires. Biochemical hypoglycaemia was defined as a blood glucose measurement below $3 \mathrm{mmol} / \mathrm{l}$ and was assessed by one monthly self-monitored 5-point blood glucose profile (before breakfast, lunch, and dinner, at bedtime, and at 3 a.m.). The proportion of 
Table 1. Clinical characteristics of 171 participants with Type 1 diabetes. Shown are data on the entire cohort and subgroups according to $A C E$ genotype. Values are mean (SD) or percentage when indicated

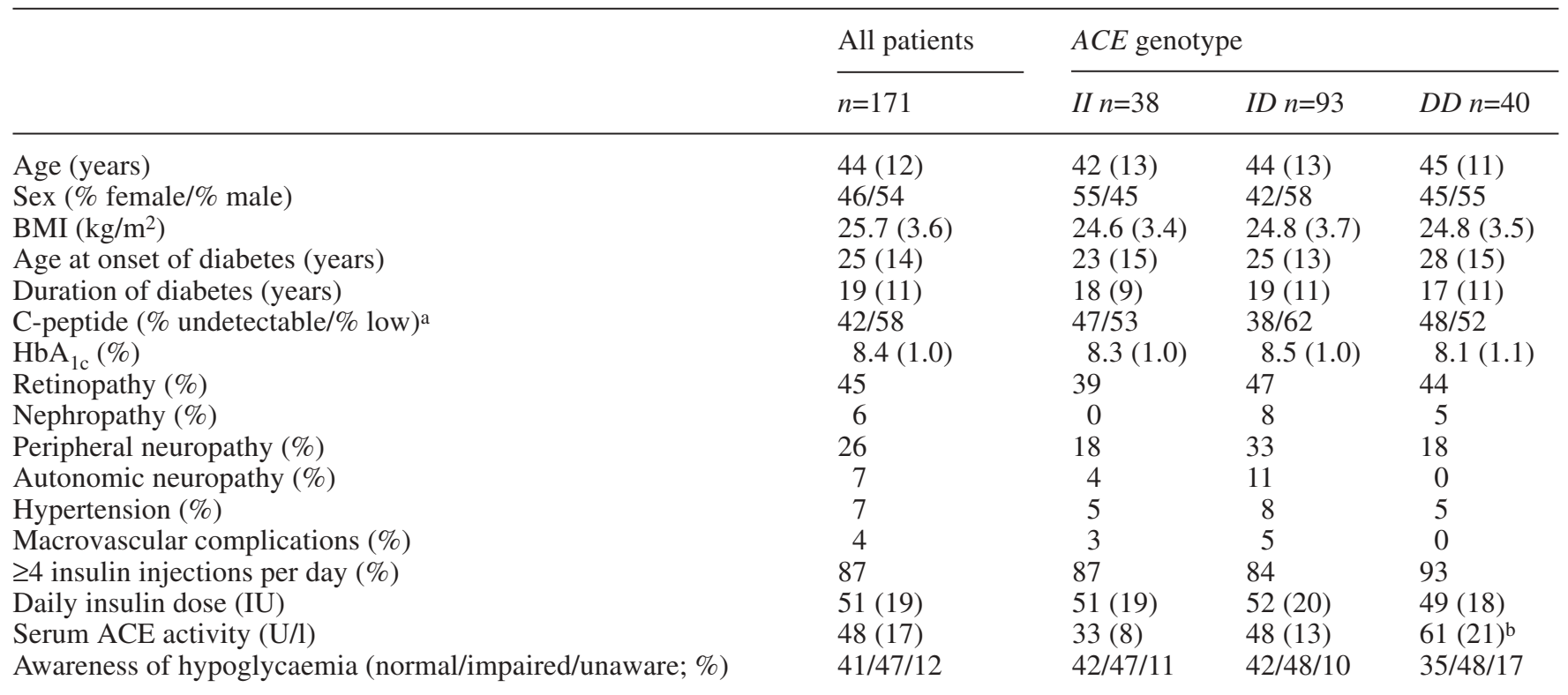

a Undetectable: $<10 \mathrm{pmol} / \mathrm{l}$

b Difference between genotypes: $p<0.0001$

low: $<300 \mathrm{pmol} / \mathrm{l}$ (unstimulated) or $<600 \mathrm{pmol} / \mathrm{l}$ (stimulated)

hypoglycaemic values (below $3.0 \mathrm{mmol} / \mathrm{l}$ ) was calculated for each subject.

Statistical analysis. Primary endpoint was the number of episodes of severe hypoglycaemia during the study period. Secondary parameters were the number of episodes of severe hypoglycaemia with coma or parenteral treatment, mean number of episodes of mild hypoglycaemia per week and the fraction of self-monitored blood glucose values below $3 \mathrm{mmol} / \mathrm{l}$. Standard descriptive and non-parametric comparative statistics were used to characterise and compare groups. The number of severe hypoglycaemic episodes and the number of severe hypoglycaemic episodes with coma were analysed by a frailty model for recurrent events (an extension of the log-linear Poisson model including a gamma-distributed variation between patients) that takes into account the highly skewed distribution of events of severe hypoglycaemia [18]. The effect of an explanatory factor is reported as relative risk with $95 \%$ confidence limits. A log-linear model was applied for the effect of serum ACE activity and for this continuous variable the relative risk is reported in a clinically relevant assay-independent manner. As median risk of subjects in the fourth quartile relative to that of subjects in the first quartile, corresponding to the risk of a subject with serum ACE activity of $64 \mathrm{U} / 1$ relative to risk of a person with serum ACE of $30 \mathrm{U} / 1$. The relative importance of serum ACE activity and established risk factors of severe hypoglycaemia were evaluated by backward stepwise multiple regression analyses. History of previous severe hypoglycaemia was not included in these analyses as this factor is not an independent factor but rather a composite product of other risk factors including state of awareness, diabetes duration, C-peptide status and ACE activity [13]. Other correlations were analysed by standard linear regression.

Data were processed by use of the SPSS software package (Version 10.0) and a non-commercial software program. A two-tailed $p$ value of less than 0.05 was considered statistically significant.

\section{Results}

During the study 193 episodes of severe hypoglycaemia (1.1 episode per patient-year) were reported during the study. These episodes were accounted for by $66(39 \%)$ patients. Coma or need for parental treatment were reported in $29 \%$ of the episodes ( 0.3 episodes per patient-year). Of the severe hypoglycaemic events $46 \%$ were classified as definite, $51 \%$ as probable, and $3 \%$ as possible. The overall mean rate of mild hypoglycaemia was 1.7 episodes per patient-week. The mean fraction of blood glucose readings below $3 \mathrm{mmol} / \mathrm{l}$ was $3.7 \%$.

The distribution of the $A C E$ genotypes (Table 1) was equal to the distribution in a large Danish population sample and was in Hardy-Weinberg equilibrium $(p=0.7)$. The mean (SD) serum ACE activity was 48 (17) U/l. Serum ACE activity was related with $A C E$ genotype $(p<0.0001)$ but no other differences in clinical characteristics between the genotypes were observed (Table 1). There was a weak positive relationship between serum ACE activity and age $\left(\mathrm{R}^{2}: 0.025\right.$; $p=0.04$ ) but not between ACE activity and duration of diabetes $(p=0.86)$. Likewise, there was a weak positive relationship between serum ACE activity and awareness of hypoglycaemia $\left(\mathrm{R}^{2}: 0.023 ; p=0.05\right)$. Serum ACE activity was not related to residual beta cell function $(p=0.46)$, daily insulin dose $(\mathrm{p}=0.59)$ or $\mathrm{HbA}_{1 \mathrm{c}}(p=0.15)$, or presence of late complications (retinopathy: $p=0.30$, nephropathy: $p=0.66$, peripheral neuropathy: $p=0.31$, autonomic neuropathy: $p=0.78$, and hypertension: $p=0.23$ ). 


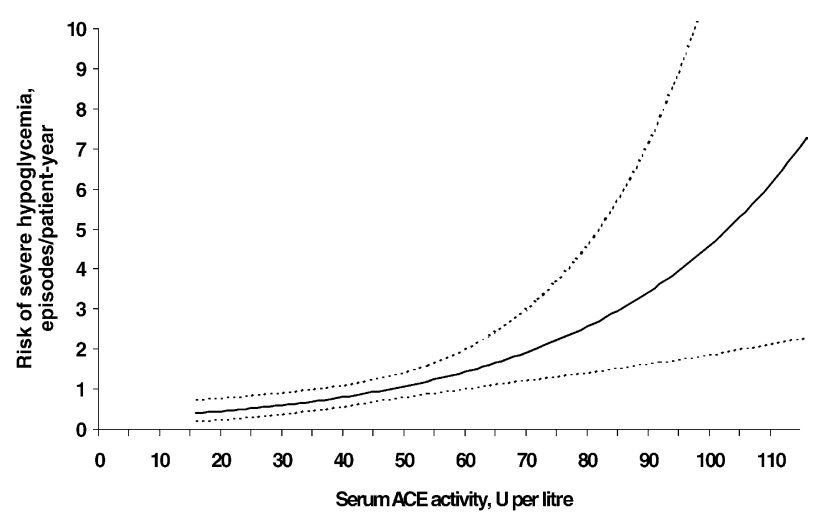

Fig. 1. Relationship between serum ACE activity and rate of severe hypoglycaemia in subjects with Type 1 diabetes. Dashed lines show 95\% confidence limits $(n=171)$

Table 2. Univariate analyses of the influence of serum ACE activity, $A C E$ genotype, and other factors on the rate of severe hypoglycaemia in 171 patients with Type 1 diabetes

\begin{tabular}{lcc}
\hline Variable & $\begin{array}{l}\text { Relative rate }^{\mathrm{a}} \\
\text { of severe hypoglycaemia } \\
\text { (95\% confidence limits) }\end{array}$ & $p$ \\
\hline Serum ACE activity & $2.7(1.5-5.0)$ & 0.0007 \\
ID genotype & $1.5(0.7-3.3)$ & 0.27 \\
DD genotype & $1.8(0.8-4.4)$ & 0.18 \\
Impaired awareness & $6.1(3.1-11.9)$ & $<0.0001$ \\
Unawareness & $10.8(4.5-25.9)$ & $<0.0001$ \\
Duration of diabetes & $1.5(1.1-2.0)$ & 0.009 \\
C-peptide status & $1.8(1.0-3.3)$ & 0.041 \\
HbA & $0.9(0.6-1.2)$ & 0.19 \\
Age & $1.2(0.9-1.5)$ & \\
\hline
\end{tabular}

$A C E$ and severe hypoglycaemia. There was a positive relationship between serum ACE activity and the rate of severe hypoglycaemia (relative rate of subjects in fourth quartile compared to subjects in first quartile: 2.7; $p=0.0007$ ) (Fig. 1, Table 2). A similar relationship was observed for the subset of events with coma (Table 3). The proportion of patients reporting severe hypoglycaemia increased with increasing serum ACE severe hypoglycaemia in the subset of $\mathrm{C}$-peptide negative subjects (relative rate of subjects in fourth quartile compared to subjects in first quartile: 4.2; $p=0.003$ ), but this did not reach statistical significance in the C-peptide positive subgroup (relative rate of subjects in fourth quartile compared to subjects in first quartile: $1.9 ; p=0.08$ ) (Fig. 2a).

There was a non-significant overall tendency towards a higher rate of severe hypoglycaemia in subjects carrying the D-allele (Table 2, 3). In the C-peptide negative subgroup, however, increased rates of severe hypoglycaemia were observed in D-allele carriers (relative rates of $I D$ and $D D$ genotype 5.3; $p=0.008$, and $6.8 ; p=0.005$, respectively) when compared to the II genotype. A multivariate analysis including serum ACE activity and genotype showed that
Table 3. Similar analyses of the subset of episodes of severe hypoglycaemia with coma or need for parenteral treatment

\begin{tabular}{lcl}
\hline Variable & $\begin{array}{l}\text { Relative rate } \\
\text { of severe hypoglycaemia } \\
\text { with coma } \\
(95 \% \text { confidence limits })\end{array}$ & \\
\hline Serum ACE activity & $2.9(1.0-8.2)$ & 0.048 \\
ID genotype & $1.2(0.3-4.2)$ & 0.93 \\
$D D$ genotype & $1.3(0.3-5.8)$ & 0.70 \\
Impaired awareness & $4.0(1.2-12.8)$ & 0.020 \\
Unawareness & $10.4(2.3-46.4)$ & 0.0023 \\
Duration of diabetes & $1.5(1.0-2.4)$ & 0.070 \\
C-peptide status & $2.1(0.8-5.6)$ & 0.14 \\
HbA & $0.8(0.5-1.3)$ & 0.45 \\
Age & $1.0(0.7-1.5)$ & 0.98 \\
\hline
\end{tabular}

a Relative rate values represent: serum ACE activity: range in serum ACE corresponding to the difference between the medians of subjects in the first and the fourth quartile; $I D$ and $D D$ genotype: compared to II genotype; state of awareness: compared to those with normal awareness; duration of diabetes: per ten-year increment; C-peptide status: C-peptide negative patients compared to $\mathrm{C}$-peptide positive subjects; $\mathrm{HbA}_{1 \mathrm{c}}$ : per one percent increase in $\mathrm{HbA}_{1 \mathrm{c}}$; age: per ten-year increment

correction for serum ACE activity eliminated the effect of the genotype [relative rates (compared to II genotype) of $I D$ and $D D$ genotype 0.81 and 0.64 ; $p=0.68]$. Therefore, only serum ACE activity is included in the following analyses.

Other risk-factors and severe hypoglycaemia. At univariate analysis, impaired awareness of hypoglycaemia, undetectable C-peptide, and increasing duration of diabetes were associated with an increased rate of severe hypoglycaemia (Table 2). In contrast, there was no relation between $\mathrm{HbA}_{1 \mathrm{c}}$ or age and rate of severe hypoglycaemia.

Multivariate analyses of severe hypoglycaemia. The relative importance of serum ACE activity and established risk factors of severe hypoglycaemia was evaluated in a multiple regression analysis including serum ACE, state of awareness of hypoglycaemia, Cpeptide status, $\mathrm{HbA}_{1 \mathrm{c}}$, age and duration of diabetes (Table 4). After exclusion of non-significant parameters, only high serum ACE activity and impaired awareness or unawareness remained important. The association between serum ACE activity and the rate of severe hypoglycaemia in both subjects with normal and impaired awareness and unawareness (relative rate of subjects in fourth quartile compared to subjects in first quartile: $4.3,1.9$ and $6.5 ; p=0.047, p=0.025$ and $p=0.040$, respectively) (Fig. 2b). There was no differential effect of ACE activity in the three groups $(p=0.28)$.

As the patients' own estimate of awareness of hypoglycaemia is influenced by previously experienced severe hypoglycaemia, a similar regression analysis 

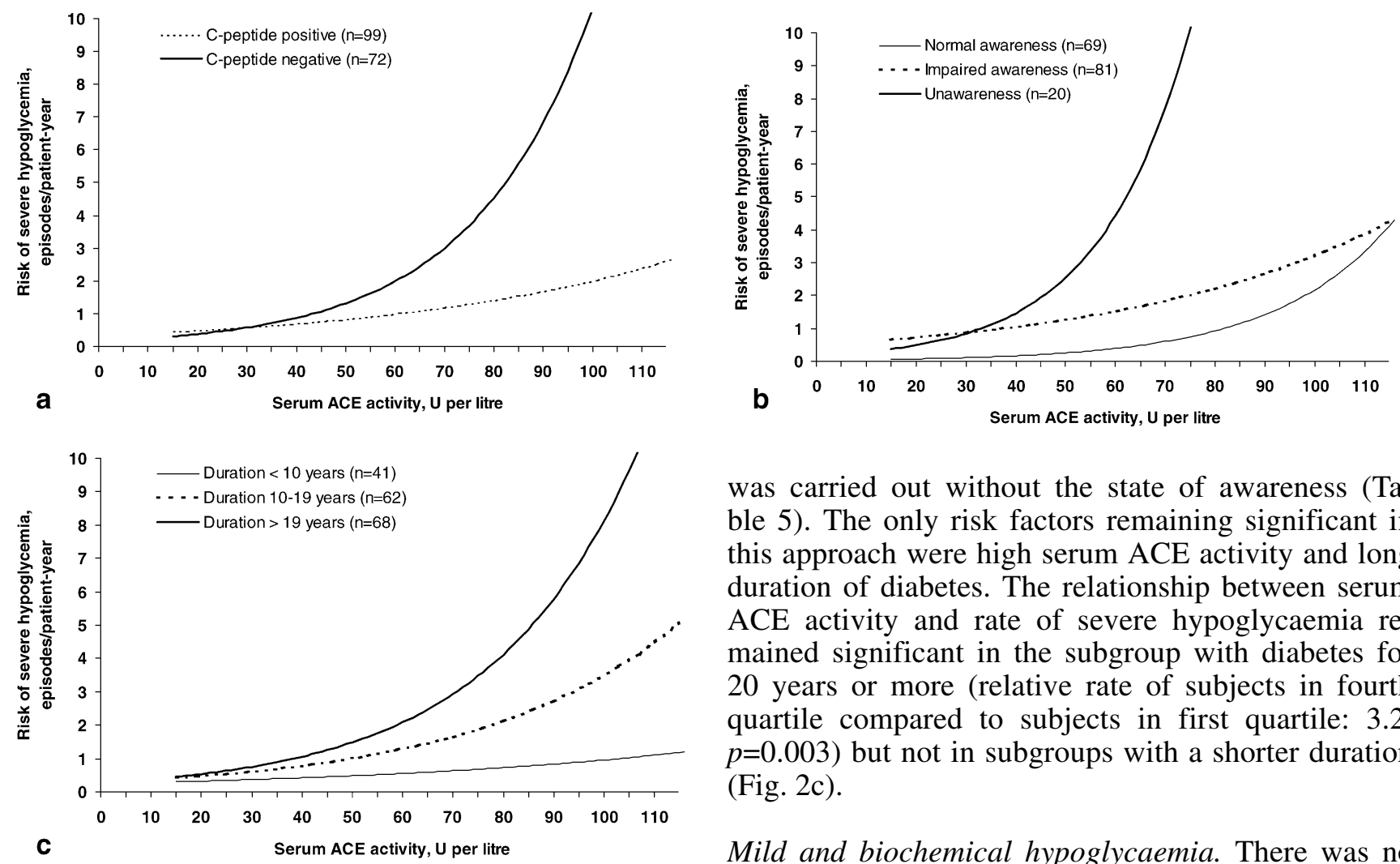

Fig. 2A-C. Relationship between serum ACE activity and rate of severe hypoglycaemia in subjects with Type 1 diabetes in subgroups according to other risk factors. A C-peptide status; $\mathbf{B}$ state of awareness; $\mathbf{C}$ duration of diabetes

Table 4. Result of stepwise regression analysis of the influence of serum ACE activity, self-estimated state of awareness of hypoglycaemia, C-peptide status, duration of diabetes, age and $\mathrm{HbA}_{1 \mathrm{c}}$ on the rate of severe hypoglycaemia in 171 subjects with Type 1 diabetes

\begin{tabular}{llr}
\hline Variable & $\begin{array}{l}\text { Relative rate } \\
\text { of severe hypoglycaemia } \\
\text { (95\% confidence limits) }\end{array}$ & $p$ \\
\hline Serum ACE activity & $\begin{array}{l}2.3(1.4-3.9) \\
\text { Impaired awareness }\end{array}$ & $\begin{array}{l}5.6(2.8-10.6) \\
\text { Unawareness }\end{array}$ \\
\hline
\end{tabular}

Table 5. Result of a similar stepwise regression analysis not including state of awareness

\begin{tabular}{lll}
\hline Variable & $\begin{array}{l}\text { Relative rate }^{\mathrm{a}} \\
\text { of severe hypoglycaemia } \\
(95 \% \text { confidence limits) }\end{array}$ & $p$ \\
\hline Serum ACE activity & $2.5(1.4-4.4)$ & 0.003 \\
Duration of diabetes & $1.3(1.0-1.8)$ & 0.045
\end{tabular}

a Relative rate values represent: serum ACE activity: range in serum ACE corresponding to the difference between the medians of subjects in the first and the fourth quartile; state of awareness: compared to those with normal awareness. duration of diabetes: per ten year increment

was carried out without the state of awareness (Table 5). The only risk factors remaining significant in this approach were high serum ACE activity and long duration of diabetes. The relationship between serum ACE activity and rate of severe hypoglycaemia remained significant in the subgroup with diabetes for 20 years or more (relative rate of subjects in fourth quartile compared to subjects in first quartile: 3.2 , $p=0.003$ ) but not in subgroups with a shorter duration (Fig. 2c).

Mild and biochemical hypoglycaemia. There was no relation between serum ACE activity and the self-reported rate of mild hypoglycaemia or proportion of self-monitored blood glucose values below $3 \mathrm{mmol} / \mathrm{l}$ ( $p=0.59$ and $p=0.60$, respectively). The rate of mild hypoglycaemia was not related to the rate of severe hypoglycaemia $(p=0.28)$ but the proportion of low self-monitored blood glucose values tended to be positively related with rate of severe hypoglycaemia (relative rate per $1 \%$ increment: $1.067 ; p=0.062$ ).

\section{Discussion}

This study identifies high naturally occurring ACE activity as a novel genetically influenced predictor of severe hypoglycaemia in unselected subjects with Type 1 diabetes. This is based on the distribution of thoroughly validated prospectively recorded events of severe hypoglycaemia according to a definition comparable to that used in the Diabetes Control and Complications Trial [1] as well as according to a more restrictive definition by the presence of coma or need for parenteral treatment. The relative rate of 2.7 among subjects with serum ACE activity in the highest quartile compared to those in the lowest quartile is in accordance with the result of our preliminary retrospective survey [13] as well as with recent preliminary data from a Swedish study in children with Type 1 diabetes [19]. The significance of the relationship between high ACE activity and the rate of severe hypoglycaemia is further stressed by our multiple regression analysis, in which serum 
ACE activity outweighed other objectively measured risk factors such as C-peptide status, duration of diabetes, age, and $\mathrm{HbA}_{1 \mathrm{c}}$. The fact that the impact of ACE activity was most significant in subjects with loss of residual beta-cell function and long duration of diabetes indicates that the influence of ACE activity is most pronounced in subjects with reduced counterregulatory capacity $[2,3]$. There was a relationship between high ACE activity and impaired awareness of hypoglycaemia, indicating that some of the effect could be due to an interaction between ACE activity and awareness, but the multiple regression analysis showed that the major effect of ACE activity was independent on state of awareness in accordance with the lack of physiological connection between ACE and awareness.

The intra-individual serum ACE activity is stable [20] and is predominantly determined by the I/D polymorphism of the $A C E$ gene [9]. In accordance with the relationship between high serum ACE activity and risk of severe hypoglycaemia, the D allele was associated with an increased risk of severe hypoglycaemia in C-peptide negative subjects. In our retrospective survey an effect was shown among all patients [13]. The concordance between the results for the genotype and for serum ACE activity adds substantially to the validity of the result and could indicate a causative relationship between high ACE activity and increased risk of severe hypoglycaemia.

Serum ACE activity can be evaluated by a simple blood test, widely available as a routine test. Due to the intra-individual stability of enzyme activity [20], measurement of serum ACE activity could be a supplement to evaluation of other risk factors in the assessment of future risk of severe hypoglycaemia. Determination of serum ACE or $A C E$ genotype might identify patients, who should be regularly evaluated with regard to residual beta-cell function and awareness of hypoglycaemia in order to prevent high rates of severe hypoglycaemia. The fact that high natural ACE activity is associated with susceptibility to severe hypoglycaemia, while in some studies it has been linked to the development of nephropathy [21] and macrovascular complications [22] indicates a narrow therapeutic window with regard to glycaemic control in subjects with high natural ACE activity.

The association between high ACE activity and the high risk of severe hypoglycaemia raises the possibility of pharmacological prevention of severe hypoglycaemia by means of ACE inhibitors. In contrast with our findings, an association between treatment for severe hypoglycaemia and use of ACE inhibitors has been indicated in a few registry based studies [23, 24]. These studies are, however, hampered by important clinical differences between cases and control group (e.g. duration of diabetes) that could account for the finding, which in accordance was not found in a controlled trial [25] or in our previous survey [13].
ACE inhibitor treatment has been shown to improve insulin sensitivity in subjects with various components of the metabolic syndrome [26], an effect with potential risk of hypoglycaemia, but no such effect seems to have been reported in normal subjects or in patients with Type 1 diabetes. Thus, the preventive potential of ACE inhibitors and angiotensin II receptor antagonists should be evaluated in Type 1 diabetic subjects at high risk of severe hypoglycaemia.

Based on the association between the I allele of the $A C E$ gene and superior performance capacity in elite endurance athletes $[10,11,12]$, the relation between serum ACE activity and risk of severe hypoglycaemia could be explained by superior cognitive or overall performance of subjects with low ACE activity during hypoglycaemia. This is supported by the fact that measures of mild and biochemical hypoglycaemia were not affected by serum ACE activity, indicating that subjects, independent of their ACE activity, experience hypoglycaemia with equal frequency but that those with low ACE activity to a greater extent are able to compensate the condition by self-treatment or maintenance of near-normal function until the next pre-scheduled meal. Hypothetically, ACE could act directly on the target organs similarly to what is observed during hypoxia [27] or indirectly via the counterregulatory response [28]. In similarity with the effect of training in muscle of non-diabetic human subjects with the II genotype [29], repetitive exposure to hypoglycaemia in subjects with low ACE activity might increase metabolic efficiency, which could be beneficial for maintenance of function during subsequent episodes of hypoglycaemia. Furthermore, low ACE activity could mediate resistance against - or reduced production of - toxic substances, e.g. reactive oxygen species in fuel deficient tissues caused by either decreased angiotensin II production or bradykinin degradation. This is supported by the activation of the renin-angiotensin system during experimental hypoglycaemia in humans [30] and the finding of high levels of angiotensin II to induce intracellular oxidative stress [31] and that bradykinin seems responsible for the beneficial effect on cardiac nitric oxide induced by ACE inhibitors [32]. Alternatively, a low ACE activity could enhance substrate mobilisation by interference with hormonal counterregulation, e.g. the response of $[28,33]$ or sensitivity to $[34,35]$ catecholamines that constitute the primary hormonal defence against hypoglycaemia in Type 1 diabetes when the glucagon response is lost.

The overall rate of severe hypoglycaemia of $1.1 \mathrm{ep}-$ isode per patient-year in this study was comparable to the result of other studies of unselected cohorts from western Europe [14, 36, 37]. These figures are all higher than those of some other studies [38], including the Diabetes Control and Complications Trial [1]. The discrepancy is probably explained by differences in definition and recording of severe hypoglycaemia and 
in a different selection of patients rather than by a real difference in incidence among comparable subjects.

Conclusively, in terms of hypoglycaemia, our study introduces evaluation of genetic factors to explain the highly varying individual susceptibility to severe hypoglycaemia and future studies might show if other functional genetic polymorphisms influence the risk of severe hypoglycaemia. In a broader perspective, our study adds to the impression of an impact of ACE activity on basic human metabolism in situations with limited substrate availability and could thereby contribute to the emerging understanding of mechanisms underlying the beneficial metabolic effects of ACE inhibition [39].

Acknowledgements. This study was funded by grants from: The Foundation of $\mathrm{H}$. Jensen and wife, The Foundation of O.B. Nielsen, The Foundation of Region 3, and The Research Foundation of Frederiksborg County. B. Agerholm-Larsen was supported by a grant from The Danish Heart Association and U. Pedersen-Bjergaard was supported by a grant from Novo Nordisk A/S, Bagsværd, Denmark. We thank research nurses P. Banck and T. Larsen for careful handling of patients and data. Research technicians M. Pedersen, K. Velin and M. Wolf, and G. Sölétormos, M.D., D.M.Sc., the Research Unit at the Clinical Biochemical Department, Hillerød Hospital, are thanked for cooperation. Technician H. Damm at the Department of Clinical Biochemistry, Herlev University Hospital, is thanked for his cooperation and performance of the ACE related analyses. The staff at the Outpatient Diabetes Clinic, Department of Internal Medicine F, Hillerød Hospital, are acknowledged for their cooperation during the patient recruitment phase.

\section{References}

1. Diabetes Control and Complications Trial Research Group (1993) The effect of intensive treatment of diabetes on the development and progression of long-term complications in insulin-dependent diabetes mellitus. N Engl J Med 329: 977-986

2. Gross TM, Mastrototaro JJ, Fredrickson LP (2000) Detection of unseen hypoglycemia using continuous glucose monitoring Diabetologia 43 [Suppl 1]: A5 (Abstract)

3. Amiel SA, Gale E (1993) Physiological responses to hypoglycemia. Counterregulation and cognitive function. Diabetes Care 16 [Suppl 3]: 48-55

4. Cryer PE (1999) Hypoglycaemia is the limiting factor in the management of diabetes. Diabetes Metab Res Rev 15: 2-46

5. Frier BM, Fisher BM (1999) Impaired hypoglycaemia awareness. In: Frier BM, Fisher BM (eds) Hypoglycaemia in clinical diabetes. 1st edn. Wiley, Chichester, pp 111-146

6. The Diabetes Control and Complications Trial Research Group (1997) Hypoglycemia in the Diabetes Control and Complications Trial. Diabetes 46: 271-286

7. Galassetti P, Mann S, Tate D, Neill RA, Costa F, Wasserman DH, Davis SN (2001) Effects of antecedent prolonged exercise on subsequent counterregulatory responses to hypoglycemia. Am J Physiol 280: E908-E917

8. Heller S, Cryer P (1991) Reduced neuroendocrine and symptomatic responses to subsequent hypoglycemia after 1 episode of hypoglycemia in nondiabetic humans. Diabetes 40: $223-226$
9. Rigat B, Hubert C, Alhenc-Gelas F, Cambien F, Corvol P, Soubrier F (1990) An insertion/deletion in the angiotensin I-converting enzyme gene accounting for half the variance of serum enzyme levels. J Clin Invest 86: 1343-1346

10. Montgomery HE, Marshall R, Hemingway Het al. (1998) Human gene for physical performance. Nature 393: 221-222

11. Gayagay G, Yu B, Hambly B et al. (1998) Elite endurance athletes and the ACE I allele - the role of genes in athletic performance. Hum Genet 103: 48-50

12. Myerson S, Hemingway H, Budget R, Martin J, Humphries S, Montgomery H (1999) Human angiotensin I-converting enzyme gene and endurance performance. J Appl Physiol 87: $1313-1316$

13. Pedersen-Bjergaard U, Agerholm-Larsen B, Pramming S, Hougaard P, Thorsteinsson B (2001) Activity of angiotensin-converting enzyme and risk of severe hypoglycaemia in type 1 diabetes mellitus. Lancet 357: 1248-1253

14. Pramming S, Thorsteinsson B, Bendtson I, Binder C (1991) Symptomatic hypoglycaemia in 411 type 1 diabetic patients. Diabet Med 8: 217-222

15. Gold AE, MacLeod KM, Frier BM (1994) Frequency of severe hypoglycaemia in patients with type 1 diabetes with impaired awareness of hypoglycaemia. Diabetes Care 17: 697-703

16. Clarke WL, Gonder-Frederick L, Julian D, Schlundt D, Polonsky W (1995) Reduced awareness of hypoglycemia in IDDM adults: a prospective study of hypoglycemic frequency and associated symptoms. Diabetes Care 18: 517-522

17. Agerholm-Larsen B, Nordestgaard BG, Steffensen R, Sørensen TI, Jensen G, Tybjærg-Hansen A (1997) ACE gene polymorphism: ischemic heart disease and longevity in 10,150 individuals. A case-referent and retrospective cohort study based on the Copenhagen City Heart Study. Circulation 95: 2358-2367

18. Hougaard P (2000) Analysis of Multivariate Survival Data. 1 st edn. Springer, Heidelberg

19. Nordfeldt S, Ludvigsson J (2001) Higher rate of severe hypoglycemia associated to higher s-ACE in children and adolescents with type 1 diabetes. J Pediatr Endocrinol Metab 14 [Suppl 3]: 1033 (Abstract)

20. Ribichini F, Steffenino G, Dellavalle A et al. (1998) Plasma activity and insertion/deletion polymorphism of angiotensin I-converting enzyme. A major risk factor and a marker of risk for coronary stent restenosis. Circulation 97: $147-154$

21. Marre M, Bernadet P, Gallois Y et al.(1994) Relationships between angiotensin I converting enzyme gene polymorphism, plasma levels, and diabetic retinal and renal complications. Diabetes 43: 384-388

22. Tarnow L, Cambien F, Rossing P et al. (1995) Insertion/deletion polymorphism in the angiotensin-I-converting enzyme gene is associated with coronary heart disease in IDDM patients with diabetic nephropathy. Diabetologia 38: 798-803

23. Herings RMC, de Boer A, Stricker BHC, Leufkens HGM, Porsius A (1995) Hypoglycaemia associated with use of inhibitors of angiotensin converting enzyme. Lancet 345: 1195-1198

24. Morris AD, Boyle DI, McMahon AD et al.(1997) ACE inhibitor use is associated with hospitalisation for severe hypoglycaemia in patients with diabetes. Diabetes Care 20: 1363-1367

25. The EUCLID study group (1997) Randomised placebocontrolled trial of lisinopril in normotensive patients with insulin-dependent diabetes and normoalbuminuria or microalbuminuria. Lancet 349: 1787-1792 
26. Reneland R, Andersson PE, Haenni A, Lithell H (1994) Metabolic effects of long-term angiotensin-converting enzyme inhibition with fosinopril in patients with essential hypertension: relationship to angiotensin-converting enzyme inhibition. Eur J Clin Pharmacol 46: 431-436

27. Georgiev V, Opitz M (1999) Participation of angiotensin receptors in acute hypoxia in mice. II. Effects of angiotensin II nonpeptide receptor ligands losartan (DuP-753) and PD123319. Methods Find Exp Clin Pharmacol 21: 463-466

28. Madsen BK, Hølmer P, Ibsen H, Christensen NJ (1992) The influence of captopril on the epinephrine response to insulin-induced hypoglycemia in humans. The interaction between the renin-angiotensin system and the sympathetic nervous system. Am J Hypertens 5: 361-365

29. Williams AG, Rayson MP, Jubb M et al. (2000) The ACE gene and muscle performance. Nature 403: 614

30. Wittert GA, Espiner EA, Richards AM, Donald RA, Livesey JH, Yandle TG (1993) Atrial natriuretic factor reduces vasopressin and angiotensin II but not the ACTH response to acute hypoglycaemic stress in normal men. Clin Endocrinol (Oxf) 38: 183-189

31. Pueyo ME, Gonzalez W, Nicoletti A, Savoie F, Arnal J-F, Michel J-B (2000) Angiotensin II stimulates vascular cell adhesion molecule-1 via nuclear factor- $\kappa \mathrm{B}$ activation induced by intracellular oxidative stress. Arterioscler Thromb Vasc Biol 20: 645-651

32. Kitakaze M, Node K, Takashima S, Minamino T, Kuzuya T, Hori M (2000) Cellular mechanisms of cardioprotection afforded by inhibitors of angiotensin converting enzyme in ischemic hearts: role of bradykinin and nitric oxide. Hypertens Res 23: 253-259

33. Yonemochi H, Yasunaga $S$ et al. (1998) Mechanism of $\beta$ adrenergic receptor upregulation induced by ACE inhibition in cultured neonatal rat cardiac myocytes. Circulation 97: 2268-2273

34. Fritsche A, Stumvoll M, Grüb M, Sieslack S, Renn W, Schmülling R-M (1998) Effect of hypoglycemia on $\beta$-adrenergic sensitivity in normal and type 1 diabetic subjects. Diabetes Care 21: 1504-1510

35. Korytkowski MT, Mokan M, Veneman TF, Mitrakou A, Cryer PE, Gerich JE (1998) Reduced $\beta$-adrenergic sensitivity in patients with type 1 diabetes and hypoglycaemia unawareness. Diabetes Care 21: 1939-1943

36. MacLeod KM, Hepburn DA, Frier BM (1993) Frequency and morbidity of severe hypoglycaemia in insulin treated diabetic patients. Diabet Med 10: 238-245

37. Braak EWMT ter, Appelman AMMF, Laak MF van de, Stolk RP, Haeften TW van, Erkelens DW (2000) Clinical characteristics of type 1 diabetic patients with and without severe hypoglycemia. Diabetes Care 23: 1467-1471

38. Bott S, Bott U, Berger M, Mühlhauser I (1997) Intensified insulin therapy and the risk of severe hypoglycaemia. Diabetologia 40: 926-932

39. Yusuf S, Sleight P, Pogue J, Bosch J, Davies R, Dagenais G (2000) Effects of an angiotensin-converting-enzyme inhibitor, ramipril, on cardiovascular events in high-risk patients. The Heart Outcomes Prevention Evaluation Study Investigators. N Engl J Med 342: 145-153 